\title{
IMPACT OF PEG6000 ON THE PHYSICAL PROPERTIES OF MICROWAVE-ASSISTED ZnO NANOSTRUCTURES USING WET CHEMICAL SYNTHESIS
}

\author{
A. Kiruthiga ${ }^{1}$, R. Kannan ${ }^{2, *}$ and T.Krishnakumar ${ }^{3}$ \\ ${ }^{1}$ Department of Physics, K. S. R. College of Engineering, \\ Tiruchengode-637215, Tamilnadu, India. \\ ${ }^{2}$ Department of Physics, Kumaraguru College of Technology, \\ Coimbatore-641 049, Tamilnadu, India. \\ ${ }^{3}$ Department of Physics, Tagore Institute of Engineering and Technology, \\ Attur-636 112 Tamilnadu,India. \\ *E-mail: kannan.r.sci@kct.ac.in
}

\begin{abstract}
$\mathrm{ZnO}$ nanostructures were synthesized by wet chemical method using surfactant PEG6000 with two different molar concentrations $(0.1 \mathrm{M} \& 0.5 \mathrm{M})$. The morphology of the $\mathrm{ZnO}$ crystals was investigated by Scanning Electron Microscopy (SEM) technique. The results indicate that the presence of surfactant significantly modifies the shape and size of $\mathrm{ZnO}$ particles. In order to examine the possible changes in other properties of ZnOcharacterizations, FTIR and UV-visible spectroscopy analysis were also studied and discussed.
\end{abstract}

Keywords: Zinc oxide, SEM, PEG6000, wet chemical synthesis, and surfactants.

(C) RASĀYAN. All rights reserved

\section{INTRODUCTION}

$\mathrm{ZnO}$ is a useful semiconductor material due to the wide direct band gap (3.3 eV) and large value of excitation binding energy $(60 \mathrm{meV}) \cdot{ }^{1-4}$ Synthesis of $\mathrm{ZnO}$ nanostructures is subject to intense research lately due to very rich shapes such as wires, tubes, rods, flowers, stars, belts and hexagonal prismatic using various methods such as wet chemical method, hydrothermal and solvothermal methods ${ }^{5-10}$ Among these methods, a wet chemical method is one of the most common and promising methods for the synthesis of zinc oxide crystals. Fortunately, surfactants coupled with the wet chemical method are able to modify the surface chemistry of nanomaterials by changing their hydrophobic or hydrophilic properties. Therefore, the desired size and shape can be tailor-made. Recently, there have been lots of work on the synthesis of $\mathrm{ZnO}$ (zinc oxide) nanostructures using different surfactants like ethylenediaminetetraacetic acid (EDTA), ${ }^{11}$ sodium dodecyl sulfate (SDS),${ }^{12}$ cetyltrimethylammonium bromide (CTAB) ${ }^{13}$ It is known that size of nanoparticles can be controlled easily through the use of surfactants in the system. The electrical and magnetic properties of nanoparticles are strongly dependent on size and shape of the particles and it is essential to study the impact of surfactant on $\mathrm{ZnO}$ nanoparticles. Various surfactants can alter nanoparticle size, shape and other surface properties to different extent depending upon the molecular structure. In this work PEG6000 (polyethylene glycol) is used as the surfactant. By adding the amount of PEG6000 we can modify the size and shape of $\mathrm{ZnO}$ nanoparticles. ${ }^{14}$ Here two samples with different concentrations such as $0.1 \mathrm{M}$ and $0.5 \mathrm{M}$ were reported. The wet chemical method was adopted in the synthesis.

\section{EXPERIMENTAL}

The synthesis strategy for $\mathrm{ZnO}$ nanostructure fabrication starts with the sequence of reactions. The precursors (so-called starting materials) used for this investigation are Zinc acetate and liquid ammonia. Initially, zinc acetate was dissolved in double distilled water to obtain 0.1 molar concentration. In the same way, PEG6000 also dissolved in double distilled water to obtain 0.1 molar concentration and added with 
RASĀYAN J. Chem.

Vol. 11 | No. 1 |18-22 | January - March | 2018

zinc acetate solution drop by drop. The solution was stirred vigorously and the $\mathrm{pH}$ value of the solution was adjusted to 8 by adding liquid ammonia until to get precipitated form. After that, the prepared solution was placed in a microwave oven and irradiated for 15 minutes. The obtained product was filtered and washed with double distilled water. Finally, the sample was dried and kept in a furnace at $120^{\circ} \mathrm{C}$ for 5 hours. The structural properties of $\mathrm{ZnO}$ nanoparticles with PEG6000 was investigated by Fourier Transform Infrared Spectroscopy (FTIR), Scanning electron microscopy (SEM)and the optical properties were studied using UV visible spectroscopy.

\section{SEM Analysis}

\section{RESULTS AND DISCUSSION}

Figures- 1(a) and (b) show SEM pictures which indicate that the sample is composed of a large quantity of nanoparticle with uniform size and shape. Generally, the surfactant has a significant influence on the size and structure of resultant products. The variations in the morphology seemingly correlate with the variation in the crystallinity of the particles. The figure shows that $\mathrm{ZnO}$ synthesized at different molar ratios of PEG6000; 0.1 and 0.5 respectively. When PEG6000 was added, the surfactant may cap the $\mathrm{ZnO}$ nanorods to inhibit further lateral growth. Therefore, the increase of PEG6000 concentration limits the lateral growth of $\mathrm{ZnO}$ rods.

\section{EDAX Analysis}
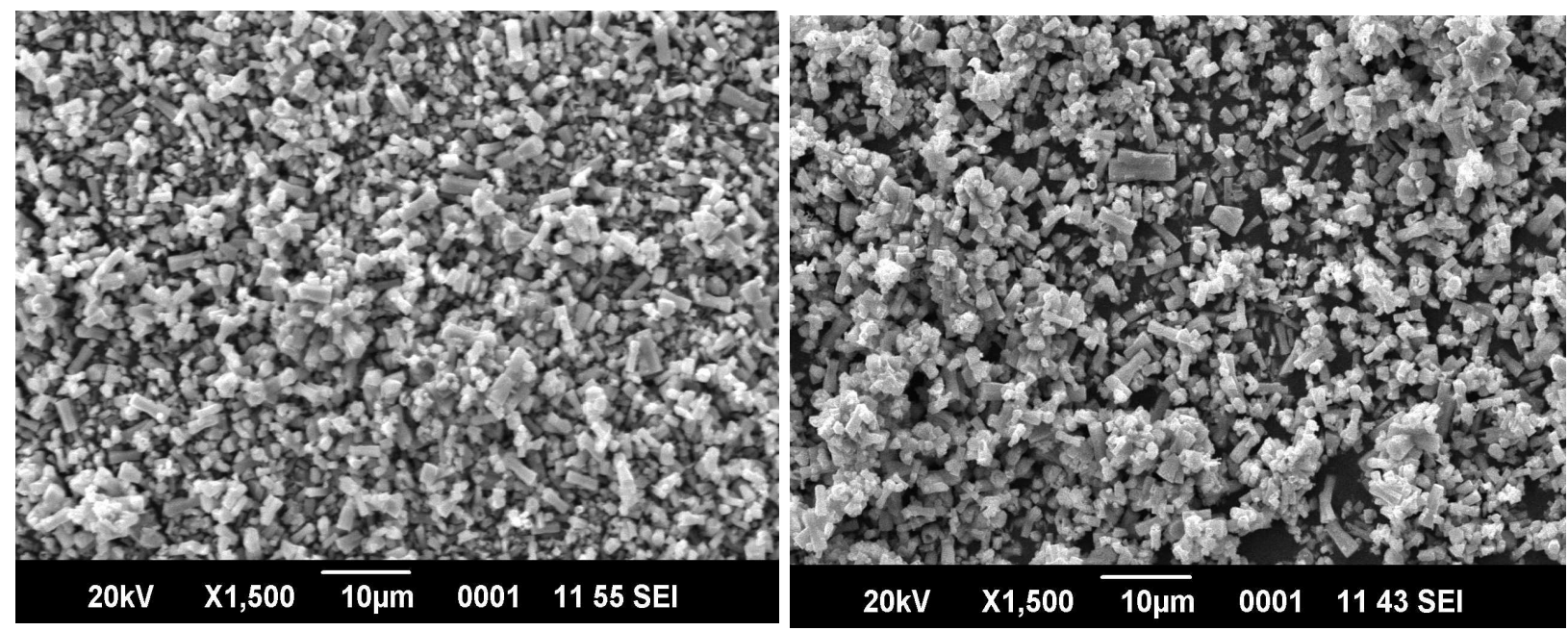

(a)

(b)

Fig.-1: (a) PEG6000 with 0.1 molar concentration (b) PEG6000 with 0.5 molar concentration

The chemical composition of the $\mathrm{ZnO}$ nanostructure was obtained from the EDAX analysis. Figures- (2a and $2 \mathrm{~b}$ ) show that the chemical compositions of the synthesized $\mathrm{ZnO}$ nanostructure with a different molar concentration of surfactant PEG6000 $(0.1 \mathrm{M}$ and $0.5 \mathrm{M})$ respectively. The EDAX pattern shows the presence of only Zinc and oxygen and hence indicates the purity of $\mathrm{ZnO}$ nanostructures.

Table-1: EDAX analysis

\begin{tabular}{l|l|l|l}
\hline S. No. & Molar Concentration & Zn wt\% & O wt $\%$ \\
\hline 1 & $0.1 \mathrm{M}$ & 89.62 & 25.99 \\
\hline 2 & $0.5 \mathrm{M}$ & 93.35 & 15.81 \\
\hline
\end{tabular}

From the Table-1 the maximum Zinc content of 93.35 weight $\%$ was obtained for $\mathrm{ZnO}$ nanostructures by adding surfactant with $0.5 \mathrm{M}$ concentration. The weight $\%$ of oxygen $\mathrm{O}$ decreases while increasing the concentration of surfactant. 
RASĀYAN J. Chem.

Vol. 11 | No. 1 |18-22 | January - March | 2018

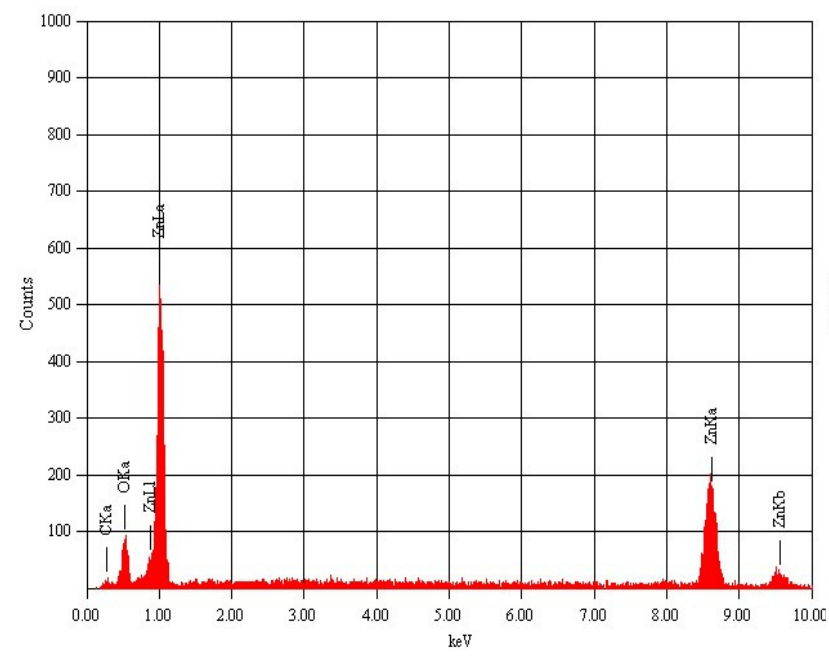

(a)

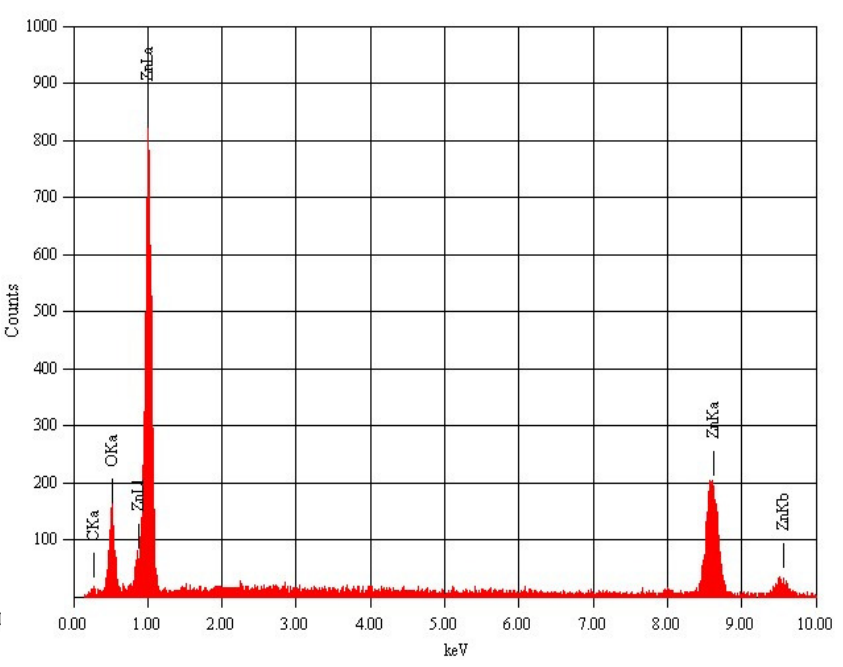

(b)

Fig.-2: (a) PEG6000 with 0.1 M Concentration(b) PEG6000 with $0.5 \mathrm{M}$ concentration

\section{UV-Visible Analysis}

The UV-Vis spectrum is studied by Perkin- Elmer Lambda 35 spectrometer with nanoparticles of $0.1 \mathrm{M}$ concentration and $0.5 \mathrm{M}$ concentration in the range of 300 to $700 \mathrm{~nm}$.
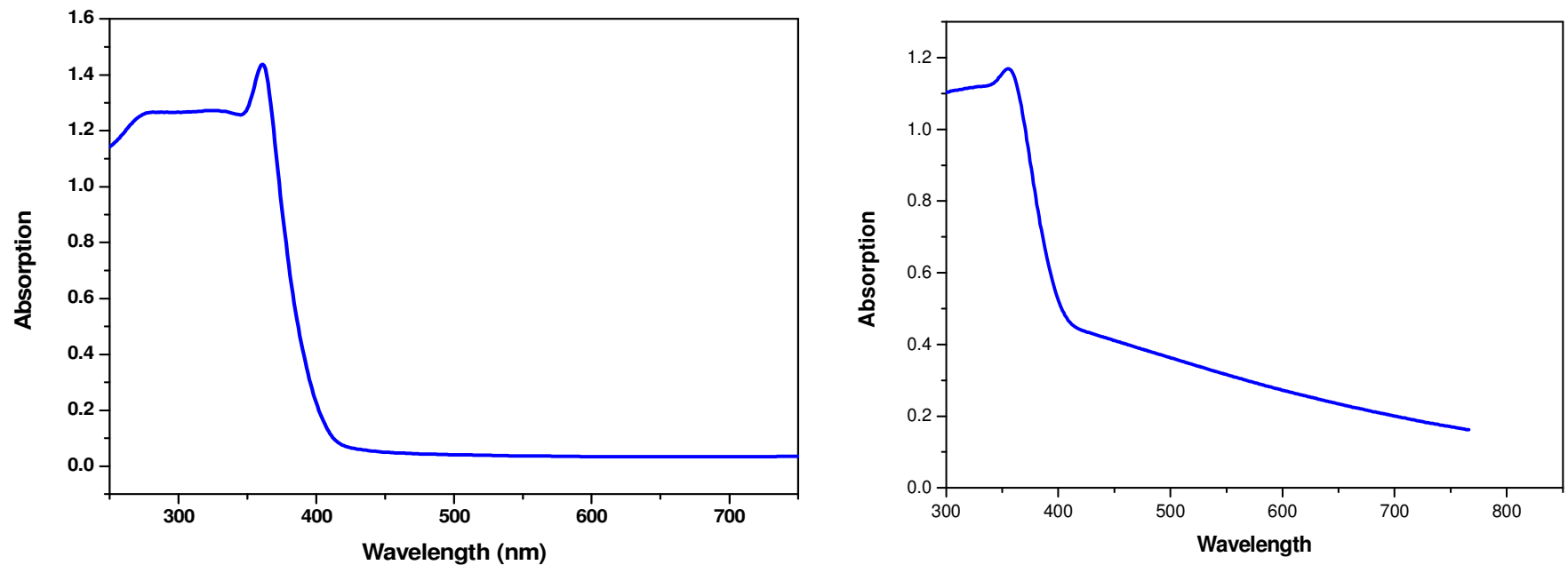

(a) (b)

Fig.-3: (a)PEG6000 with $0.1 \mathrm{M}$ concentration (b)PEG6000 with $0.5 \mathrm{M}$ concentration

The transmission range and transparency cut off wavelength are important for nanoparticles. The recorded transmittance spectrum is shown in Figures $5 \mathrm{a} \& 5 \mathrm{~b}$ for molar concentration $0.1 \mathrm{M}$ and $0.2 \mathrm{M}$. The lower cut off wavelengths are at $362.330(0.1 \mathrm{M})$ and $364.10(0.5 \mathrm{M})$. The transmittance range is about $80 \%$ for $0.1 \mathrm{M}$ concentration and $85 \%$ for $0.5 \mathrm{M}$ concentration respectively. The absorption edges are found to be 1.252 and 1.122 and hence for the fabrication of application-oriented optical devices, the modification of optical parameter such as absorption edge is extremely important.

\section{FTIR Analysis}

To analyze the adsorption of surfactants on the surface of $\mathrm{ZnO}$ nanostructures, FTIR spectrum was recorded in the range of $4000-500 \mathrm{~cm}-1$ (Figure 5a\&5b). Samples prepared using PEG6000 with two 
RASĀYAN J. Chem.

Vol. 11 | No. 1 |18-22 | January - March | 2018

different molar concentrations $0.1 \mathrm{M}$ and $0.5 \mathrm{M}$ shows quite similar bands at $3374 \mathrm{~cm}^{-1}, 1558 \mathrm{~cm}^{-1}$ and 1412 $\mathrm{cm}^{-1}$ which corresponds to $\mathrm{N}-\mathrm{H}$ stretching vibration and $\mathrm{N}-\mathrm{H}$ bending respectively. The characteristic peak of $\mathrm{ZnO}$ absorption can be clearly observed at $874.01 \mathrm{~cm}^{-1}$ and $428.00 \mathrm{~cm}^{-1}$ which clearly shows that by increasing the molar concentration of PEG6000, the peak shifted to lower wave numbers.
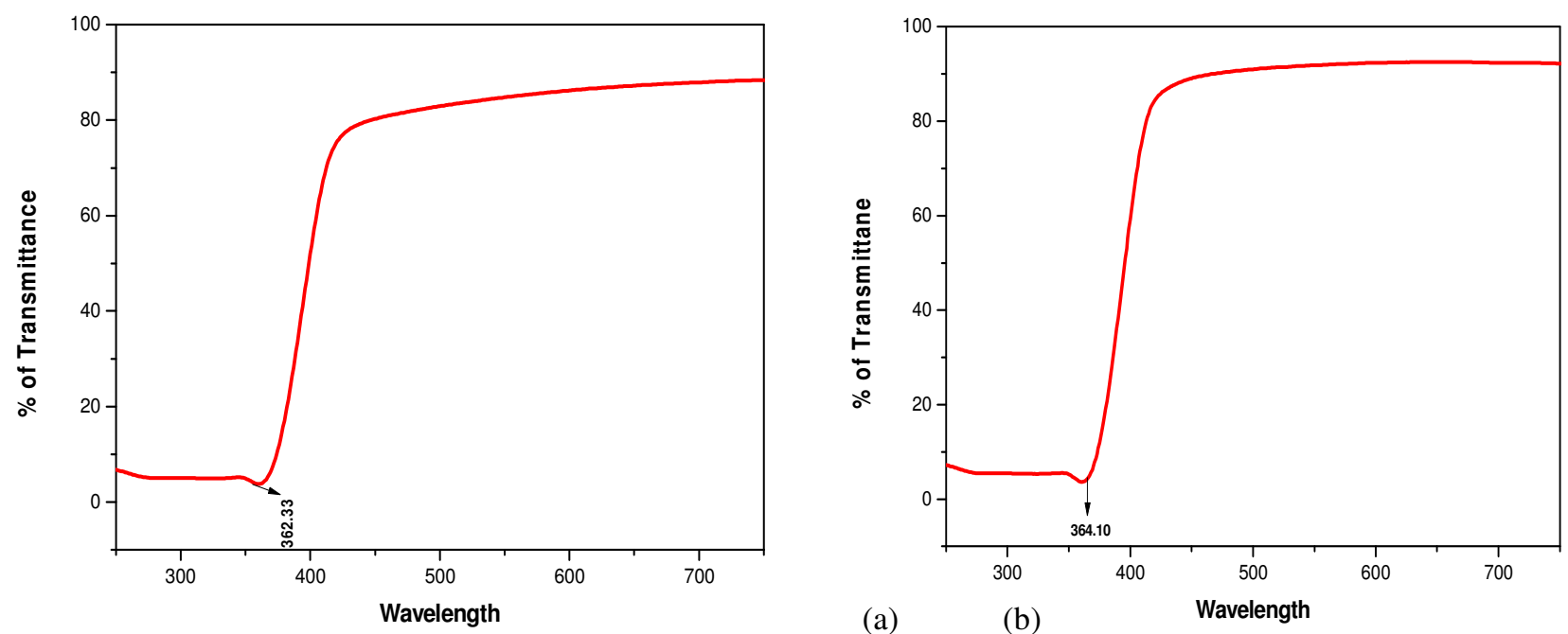

Fig.-4: (a)PEG6000 with $0.1 \mathrm{M}$ concentration(b)PEG6000 with $0.5 \mathrm{M}$ concentration
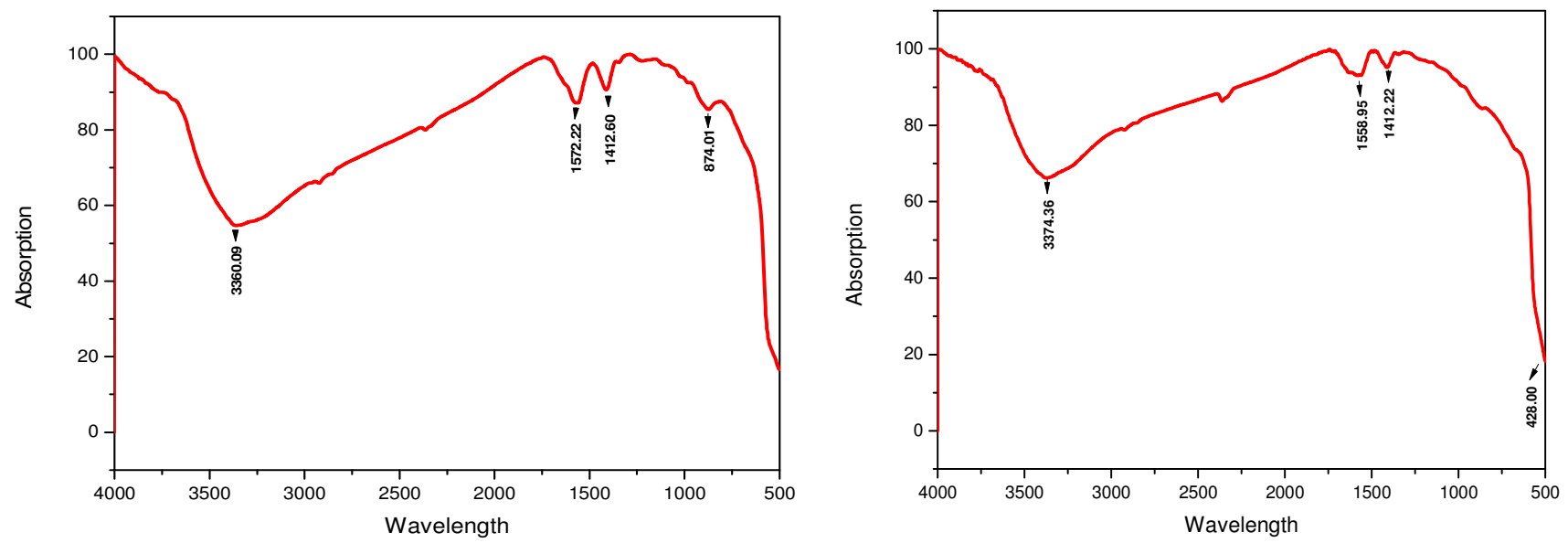

(a) (b)

Fig.-5: (a) PEG6000 with $0.1 \mathrm{M}$ concentration(b)PEG6000 with $0.5 \mathrm{M}$ concentration

Table-2: UV- VIS results

\begin{tabular}{l|l|l|l}
\hline S. No. & Molar Concentration & Absorption Edge & Cut off Wavelength (nm) \\
\hline 1 & $0.1 \mathrm{M}$ & 1.252 & 362.330 \\
\hline 2 & $0.5 \mathrm{M}$ & 1.122 & 364.10 \\
\hline
\end{tabular}

\section{CONCLUSION}

In summary, $\mathrm{ZnO}$ nanoparticles have been synthesized using a relatively simple method using PEG6000 as a surfactant. The size, structure, and morphology of the as formed $\mathrm{ZnO}$ nanoparticles are dependent on the increase of the molar concentration of the surfactants. Moreover, by increasing the molar concentration of surfactant it seems that there is a shift in the characteristic peak of $\mathrm{ZnO}$ to lower wave 
numbers. The addition of surfactant to $\mathrm{ZnO}$ nanoparticles shows the better results in improving the crystallinity and structure of $\mathrm{ZnO}$ powders which intern enhance its characteristic nature.

\section{REFERENCES}

1. L. Vayssieres, K. Keis, A. Hagfeldt and S. Lindquist, Chem. Mat., 13(12),52, (2001).

2. H. Kind, H. Yan, B. Messer, M, Law and P. Yang, Adv. Mater., 14(2), 158, (2002).

3. J. L. Yang, S. J. An, W. I. Park, G. C. Yi and W. Choi, Adv. Mater., 16(18), 1661, (2004).

4. A. Qurashi, N. Tabet, M. Faiz and T. Yamzaki, Nanoscale Res. Lett., 4 (8), 948, (2009).

5. R. A. McBride, J. M. Kelly and D. E. McCormack, J. Mater. Chem., 13, 1196, (2003).

6. R. Kannan, M. Selvambikai, I. Jeena Rajathy and S. Ananthi, Rasayan J. Chem.,10(4), 1213, (2017).

7. W. Z.Wang, B. Q. Zeng, J. Yang, B. Poudel, J. Y. Huang, M. J. Naughton and Z. F, Adv. Mater., 18(24), 3275, (2006).

8. T. Krishnakumar, R. Jayaprakash, N. Pinna, v. N. Singh, B. R. Mehta and A. R. Phani, Mater. Lett.,63(2), 242, (2008).

9. N. Tabet, R. Al Ghashani and S. Achour, Super lattice Microst., 45, 598, (2009).

10. N. Samaele, P. Amornpitoksuk and S. Suwanboon, Powder Technol., 1 (3), 243, (2010).

11. S. B. Kulkarni, U. M. Patil, R. R. Salunkhe, S. S. Joshi and C. D. Lokhande, J. Alloys Compd., 509(8), 3486, (2011).

12. G. Sun, M. Cao, Y. Wang, C. Hu, Y. Liu, L. Ren and Z. Pu, Mater. Lett., 60 (40), 2777, (2006).

13. R. Kannan, S. Ganesan, and T. M. Selvakumari, Dig. J. Nanomater. Bios., 7 (3), 1039 (2012).

14. Y. Feng, M. Zhang, M. Guo and X. Wang, Cryst. Growth Des., 10(4), 1500, (2010).

[RJC-1935/2017] 